\title{
Glass formation and unusual hygroscopic growth of iodic acid solution droplets with relevance for iodine mediated particle formation in the marine boundary layer
}

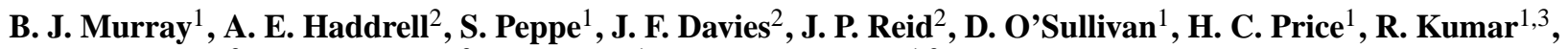 \\ R. W. Saunders ${ }^{3}$, J. M. C. Plane ${ }^{3}$, N. S. Umo ${ }^{1}$, and T. W. Wilson ${ }^{1,3}$ \\ ${ }^{1}$ School of Earth and Environment, University of Leeds, Woodhouse Lane, Leeds LS2 9JT, UK \\ ${ }^{2}$ School of Chemistry, University of Bristol, Bristol, BS8 1TS, UK \\ ${ }^{3}$ School of Chemistry, University of Leeds, Woodhouse Lane, Leeds, LS2 9JT, UK \\ Correspondence to: B. J. Murray (b.j.murray@leeds.ac.uk)
}

Received: 29 February 2012 - Published in Atmos. Chem. Phys. Discuss.: 20 March 2012

Revised: 17 August 2012 - Accepted: 28 August 2012 - Published: 25 September 2012

\begin{abstract}
Iodine oxide particles are known to nucleate in the marine boundary layer where gas phase molecular iodine and organoiodine species are produced by macroalgae. These ultra-fine particles may then grow through the condensation of other materials to sizes where they may serve as cloud condensation nuclei. There has been some debate over the chemical identity of the initially nucleated particles. In laboratory simulations, hygroscopic measurements have been used to infer that they are composed of insoluble $\mathrm{I}_{2} \mathrm{O}_{4}$, while elemental analysis of laboratory generated particles suggests soluble $\mathrm{I}_{2} \mathrm{O}_{5}$ or its hydrated form iodic acid, $\mathrm{HIO}_{3}$ $\left(\mathrm{I}_{2} \mathrm{O}_{5} \cdot \mathrm{H}_{2} \mathrm{O}\right)$. In this paper we explore the response of supermicron sized aqueous iodic acid solution droplets to varying humidity using both Raman microscopy and single particle electrodynamic traps. These measurements reveal that the propensity of an iodic acid solution droplet to crystallise is negligible on drying to $\sim 0 \%$ relative humidity (RH). On applying mechanical pressure to these droplets they shatter in a manner consistent with an ultra-viscous liquid or a brittle glass. Water retention in amorphous material at low RH is important for understanding the hygroscopic growth of aerosol particles and uptake of other condensable material. Subsequent water uptake between 10 and $20 \%$ RH causes their viscosity to reduce sufficiently that the cracked droplets flow and merge. The persistence of iodic acid solution in an amorphous state, rather than a crystalline state, suggests they will more readily accommodate other condensable material and are therefore more likely to grow to sizes where they
\end{abstract}

may serve as cloud condensation nuclei. On increasing the humidity to $\sim 90 \%$ the mass of the droplets only increases by $\sim 20 \%$ with a corresponding increase in radius of only $6 \%$, which is remarkably small for a highly soluble material. We suggest that the small growth factor of aqueous iodic acid solution droplets is consistent with the small aerosol growth factors observed in previous experiments.

\section{Introduction}

In seaweed-rich coastal regions there is a marked increase in the number of nucleation mode particles observed during daytime low tides when macroalgal species are exposed to air and emit large quantities of molecular iodine (McFiggans et al., 2010; Saiz-Lopez et al., 2012). Particle production is driven by biogenic emissions of iodine vapours that rapidly undergo photochemical processing to produce gas phase iodine oxides such as IO and OIO which undergo further reactions leading to higher oxides which can condense to form new particles (Saiz-Lopez et al., 2012; O'Dowd and Hoffmann, 2005). Under suitable conditions these nanometre sized particles may grow, through the condensation of other condensable vapours (Mäkelä et al., 2002; Saunders et al., 2010), to sufficiently large sizes that they can serve as cloud condensation nuclei (McFiggans et al., 2010). At present it is unclear if iodine production from open ocean sources can be sufficiently strong to lead to significant particle formation 
over the open ocean (Saiz-Lopez et al., 2012; Mahajan et al., 2010).

There has been some debate in the literature over the most likely composition of iodine oxide particles with insoluble $\mathrm{I}_{2} \mathrm{O}_{4}$ and the soluble $\mathrm{I}_{2} \mathrm{O}_{5}$ being identified as the most likely candidates (Jimenez et al., 2003; O'Dowd and De Leeuw, 2007). Iodine oxide particles generated in the laboratory through a range of processes have small hygroscopic growth factors (Saunders et al., 2010; Jimenez et al., 2003; McFiggans et al., 2004). In general, a small growth factor indicates a weakly soluble material or an insoluble material internally mixed with a small amount of soluble material (Swietlicki et al., 2008; Väkevä et al., 2002). Since $\mathrm{I}_{2} \mathrm{O}_{5}$ is highly soluble $(263.2 \mathrm{~g}$ per $100 \mathrm{~g}$ of water at $298 \mathrm{~K}$, Kumar et al., 2010), Jimenez et al. (2003) concluded that $\mathrm{I}_{2} \mathrm{O}_{4}$ was the most likely composition of iodine oxide particles. However, elemental analysis of particles generated photochemically from $\mathrm{I}_{2}$ in the presence of $\mathrm{O}_{3}$ revealed a composition consistent with $\mathrm{I}_{2} \mathrm{O}_{5}$ (Saunders and Plane, 2005). $\mathrm{I}_{2} \mathrm{O}_{4}$ exists as an insoluble crystalline solid which slowly disproportionates to $\mathrm{I}_{2}$ and $\mathrm{HIO}_{3}$ when immersed in water at room temperature, or even just exposed to humid air for a prolonged period (Daehlie and Kjekshus, 1964). Hence, if $\mathrm{I}_{2} \mathrm{O}_{4}$ forms in the humid marine boundary layer it may later convert to iodic acid solution (Saiz-Lopez et al., 2012). Ultrafine particles (8 and $10 \mathrm{~nm})$ sampled during low tide particle "bursts" at Mace Head in Ireland are also reported to have a characteristic hygroscopic growth factor of less than 1.1 at an $\mathrm{RH}$ of $90 \%$ (Väkevä et al., 2002), ruling out sulfate or sea salt aerosol which are known to have much greater growth factors. These natural particles are likely to contain a mixture of condensable material; for example, Mäkelä et al. (2002) showed that the ultrafine particles sampled at low-tide periods at the same coastal location contained iodine as well as sulphur. In addition, Vaattovaara et al. (2006) report significant amounts of organic compounds contribute to particles of 5-6nm, whereas particles smaller than 3-4 nm are dominantly made of iodine oxides.

The physical state of the initially formed atmospheric iodine oxide particles and those formed in the laboratory is an unresolved issue and the physical state of aerosol particles on drying is critical for understanding hygroscopic growth measurements (Mikhailov et al., 2009). Aerosol can exist in a liquid, crystalline solid, amorphous solid or amorphous semi-solid state. Amorphous substances by definition have no long range order, in contrast to crystalline materials, and an amorphous material is said to become glassy when its viscosity exceeds $10^{12} \mathrm{~Pa} \mathrm{~s}$ (Angell, 2002). At such extreme viscosities an amorphous material will have physical properties consistent with that of a solid. At lower viscosities materials can exist as liquids, ultra-viscous liquids, rubbers or gels (Mikhailov et al., 2009). Gels are defined as a twophase mixture in which one phase is a solid matrix while the other retains some mobility within the matrix. Rubbers form when intermolecular bonding between molecules forms a complex cross linked matrix. Ultra-viscous liquids may exhibit viscous flow on long timescales, but if subjected to a shear force on a short time scale they can shatter. An example of an ultra-viscous liquid is pitch which shatters when hit with a hammer, but flows on a decadal timescale with an estimated viscosity of $10^{8} \mathrm{~Pa}$ s (Edgeworth et al., 1984). On cooling, rubbers, gels and ultra-viscous liquids can form a glass at the glass transition temperature. In addition, water serves as a plasticiser in many amorphous materials and reduction of relative humidity may also cause an amorphous material to become semi-solid or glassy (Mikhailov et al., 2009).

It has been suggested that aerosol particles can become glassy at the very low temperatures found at the tropopause (Murray, 2008; Zobrist et al., 2008) and it was later shown that this may influence cirrus cloud formation through heterogeneous ice nucleation (Murray et al., 2010b; Wagner et al., 2012; Wilson et al., 2012; Wang et al., 2012). It has also been shown that on drying atmospherically relevant aqueous droplets at temperature relevant for much of the troposphere that they can become semi-solid or even glassy rather than crystallise (Mikhailov et al., 2009; Tong et al., 2011; Bodsworth et al., 2010) and that the rate of exchange of water with air is greatly reduced at low humidity (Zobrist et al., 2011; Tong et al., 2011). Recent work also shows that secondary organic aerosol may exist in an amorphous solid state (Virtanen et al., 2010; Koop et al., 2011). The existence of aerosol particles in an amorphous solid or semi-solid state is important because their growth through uptake of condensable vapours will be reduced relative to a liquid droplet since diffusion into their interior is limited (Shiraiwa et al., 2011). For iodine oxide particles in the humid marine boundary layer kinetic limitations to growth are not likely to be significant, but knowledge of the phase state at low humidity is critical for understanding hygroscopic growth measurements. The behaviour of organic solutions contrasts strongly with typical atmospherically relevant inorganic solutions, such as $\mathrm{NaCl}$ or $\mathrm{NH}_{4}\left(\mathrm{SO}_{4}\right)_{2}$, which readily crystallise at low $\mathrm{RH}$ (Martin, 2000; Onasch et al., 1999; Pant et al., 2006). However, Mikhailov et al. (2009) also discussed a number of inorganic solution aerosol species which tend not to exhibit prompt crystallisation such as $\mathrm{NH}_{4} \mathrm{HSO}_{4}$ and $\mathrm{NH}_{4} \mathrm{NO}_{3}$ and it has been suggested that the freeze concentrated solution in frozen inorganic solution droplets is glassy (Murray and Bertram, 2008, 2007). Also, delayed water transport in amorphous particles of $\mathrm{MgSO}_{4}$ at $\mathrm{RHs}$ below $40 \%$ has been reported, with $\mathrm{MgSO}_{4}$ persisting in an amorphous gel state to $0 \%$ RH without crystallisation (Li et al., 2011; Chan et al., 1998).

Previous work suggests that iodic acid droplets may become very viscous at low humidity (Kumar et al., 2010; Ivanov et al., 1985). Kumar et al. (2010) quantified the deliquescence RH (DRH) of crystalline $\mathrm{I}_{2} \mathrm{O}_{5}$ and $\mathrm{HIO}_{3}$ as well as studying the effect of the drying of iodic acid solution droplets (note that $\mathrm{I}_{2} \mathrm{O}_{5}$ and $\mathrm{HIO}_{3}$ share a common aqueous 
phase, which we refer to as an iodic acid solution). The crystalline solids were shown to have DRH values in excess of $80 \%$ below $300 \mathrm{~K}$, but when the micrometer sized solution droplets were gradually dried out to $0 \%$ RH they did not appear to crystallise when viewed with an optical microscope. Kumar et al. (2010) suggested that the droplets may not have crystallised instead becoming extremely viscous even to the extent of possibly forming a glass at low RH. This is intriguing because it suggests that if iodine oxide particles are either produced in an aqueous liquid state or as crystalline particles that have undergone deliquescence in the humid marine boundary layer, they will persist in an amorphous (liquid or solid) state.

In this paper, we use a Raman microscope coupled to a temperature and humidity controlled stage to explore the physical state of micrometer sized iodic acid solution droplets and two types of electrodynamic balances to quantify the hygroscopic growth and probe the rate at which they lose water. An advantage of using micrometer sized droplets is that they are large enough to justify us neglecting the influence of the surface curvature term in determining particle size, hence the measurements provide a clear picture of the thermodynamics of iodic acid solution and the potential departure of iodic acid aerosol from a thermodynamically equilibrated state. These measurements allow us to address two issues. Firstly, the thermodynamic measurements provide crucial equilibrium data for interpreting hygroscopic growth of freshly nucleated particles in the marine boundary layer. Secondly, iodic acid is a further example of the formation of amorphous kinetically arrested states which has implications for how growth factor measurements are interpreted. This has consequences for interpreting atmospheric and laboratory measurements.

\section{Experimental}

\subsection{Raman microscope and humidity controlled stage}

A diagram of the humidity controlled stage coupled to the Raman microscope system is shown in Fig. 1. Crystalline $\mathrm{HIO}_{3}$ particles (99.5\%, Sigma-Aldrich) with dimensions of several 10s of micrometers were mounted on a silanised glass cover slip. Similar cover slips have been used in previous nucleation studies and shown not to catalyse nucleation (Murray et al., 2010a, 2011a, b; Knopf and Lopez, 2009; Dymarska et al., 2006; Broadley et al., 2012; Koop et al., 1998). The cell was constructed of Teflon and sealed on the base with an O-ring with a window (cover slip) on top through which the sample could be viewed. The humidity in the nitrogen flowing over the particles was controlled by passing nitrogen gas through a bubbler immersed in a temperature controlled bath and diluted using mass flow controllers (MKS 1179) to produce the desired humidity. The humidity of the gas downstream of the cell was recorded with a dew/frost

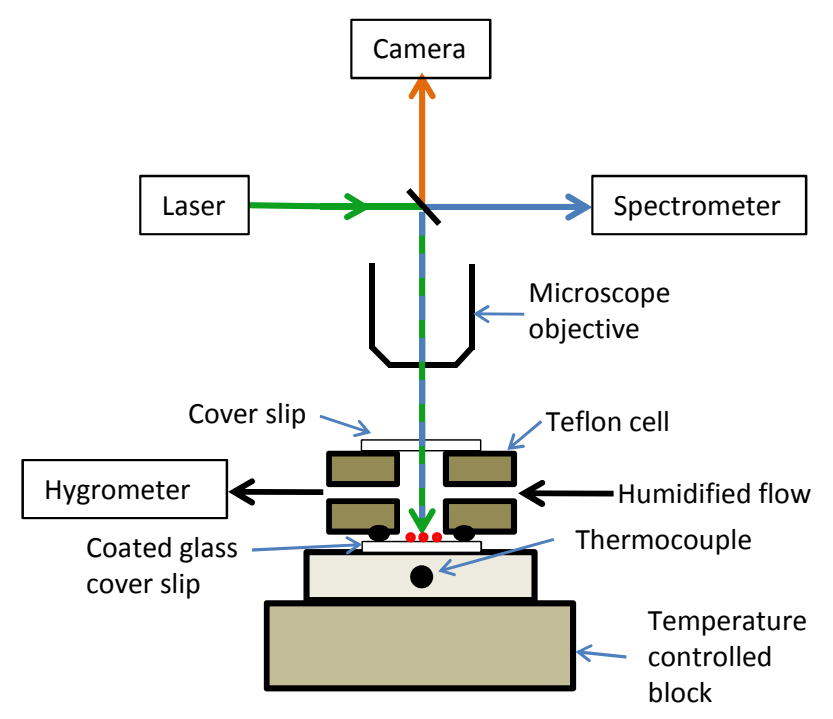

Fig. 1. Diagram of the humidity controlled stage coupled to a Raman microscope system used in this study. Not to scale.

point hygrometer (General Eastern D-2 sensor). The temperature of the stage was set using a re-circulating chiller and the temperature of the sample was determined from the average of two T-type thermocouples embedded in the stage immediately below the sample. In these experiments the temperature was set to $294 \pm 0.5 \mathrm{~K}$. The temperature of the stage and dew point of the gas were used to derive the $\mathrm{RH}$ of the gas above the sample according the parameterisations of Murphy and Koop (2005).

The humidity and temperature controlled stage was mounted on the automated x-y translation stage of the Raman system which allowed the stage to move independently of the objective and Raman system. Raman microscopy enabled us to optically view particles under magnification and then probe individual particles by focusing a laser onto them. The resulting inelastic Raman emission was then collected and analysed using a spectrometer. The Raman spectrum provides a means of unambiguously identifying chemical compounds and determining phase and phase changes (Reid et al., 2007). Our experiments were performed with a $514 \mathrm{~nm}$ laser coupled to a Renishaw inVia Raman microscope system equipped with a Leica microscope and Olympus 20x long working distance objective.

\subsection{Electrodynamic balance (EDB) instruments}

Two separate electrodynamic balances (EDBs) where used in these experiments: one with a double ring electrode design and the second with a concentric cylindrical electrode design. The description and standard operation of the double ring EDB has been published previously (Hargreaves et al., 2010). Briefly, an aqueous iodic acid (from the same source as used in Raman experiments) solution was placed into the 
reservoir of a droplet-on-demand dispenser (GeSiM, A-010$006,30 \mu \mathrm{m}$ orifice). The dispenser was positioned directly $\sim 2 \mathrm{~mm}$ above the induction electrode, to which a $+175 \mathrm{~V}$ DC voltage is applied, and $\sim 12 \mathrm{~cm}$ above the double ring electrodes of the EDB, to which an AC potential $(2 \mathrm{kV}(0-\mathrm{P})$, $50-200 \mathrm{~Hz}$ ) was applied. The field generated by the induction electrode imparted a mirror charge onto the droplet as it was ejected from the dispenser. The presence of this net charge enabled the droplet to be levitated by the AC field generated by the ring electrodes. A $632 \mathrm{~nm} \mathrm{He}-\mathrm{Ne}$ laser was used to illuminate the droplet.

The size of the levitated droplet was estimated using two different methods. The relative mass of the droplet was measured by monitoring the amplitude of the DC offset to the $\mathrm{AC}$ field required to hold the droplet at a fixed position (null point). The RH in the EDB was controlled by varying the relative proportion of dry and humidified nitrogen gas flows with a net flow rate held constant at $200 \mathrm{sccm}$. To generate the humidified airflow, nitrogen was passed through a 21 bubbler filled with pure water $(18 \mathrm{M} \Omega \mathrm{cm})$. The mixture of humidified and dry air was passed through an electrostatic precipitator (ESP) prior to the EDB. The temperature and relative humidity of the airflows entering and leaving the EDB were measured using two Honeywell probes (HIH-4602-A/C Series). The RH was then ramped from $<20 \%$ to $>90 \%$ then back to $<20 \%$ over a period of $\sim 24 \mathrm{~h}$, with an hour given to equilibrate at each $10 \%$ increase in $\mathrm{RH}$ and two hours given to equilibrate each $10 \%$ decrease in $\mathrm{RH}$.

A second electrodynamic balance, based on concentric cylindrical electrodes, was used to observe mass transfer into dry conditions from droplets of known size and composition. A detailed description of the technique and method utilized is described by Davies et al. (2012). A key benefit of this technique is the ability to accurately determine initial size and composition, allowing an estimate of the dry size. The elastic scattering of the laser by the droplet in the angular range of $42^{\circ}$ to $50^{\circ}$ was collected with a CCD and the angular separations between the peaks in the fringe pattern were used to estimate the radius of the droplet (Glantschnig and Chen, 1981). Each measured scattering pattern was compared with Mie theory simulations and the best fit size was obtained for each frame. This estimation results in an error in absolute radius of less than $50 \mathrm{~nm}$, which is a significantly more sensitive measure of changes in size than the DC offset. The timescales accessible with the instrument range from sub sub-100 ms to many hours, with a resolution down to $10 \mathrm{~ms}$, allowing both the initial rapid evaporation and the slow approach to equilibrium to be readily measured.

\section{Results and discussion}

\subsection{Raman study of $\mathrm{HIO}_{3}$ solution droplets}

Crystalline $\mathrm{HIO}_{3}$ particles were ground with pestle and mortar and deposited directly onto the silanised glass slide. The slide was then mounted on the RH and temperature controlled stage. The temperature of the cell was maintained at $294 \pm 0.5 \mathrm{~K}$ throughout the experiment and the RH was initially set to $48.5 \%$. The Raman spectrum and accompanying image of the crystal are shown in Fig. 2a. The RH was increased (or decreased) in steps and the particles allowed to equilibrate for at least $10 \mathrm{~min}$ before a Raman spectrum was recorded. No change in the particles was observed until $82.5 \%$ RH when the image of the droplet clearly shows water uptake and an aqueous droplet forming around a crystal (Fig. 2c). The corresponding spectrum is still dominated by the features of the crystalline material, but a weak water peak can be seen to appear centred at about $3400 \mathrm{~cm}^{-1}$. On increasing the RH to $83.5 \%$ (Fig. 2d) the crystal can be seen to have fully dissolved in the image and the Raman spectrum has altered substantially. The peaks associated with $\mathrm{IO}_{3}$ below $1000 \mathrm{~cm}^{-1}$ (see Table 1) all become much broader and a clear $\mathrm{OH}$ stretch signal appears around $3400 \mathrm{~cm}^{-1}$ which is indicative of liquid water. Kumar et al. (2010) determined that the DRH of $\mathrm{HIO}_{3}$ at $294 \mathrm{~K}$ was $84 \pm 1 \%$, which is consistent with the RH at which we observe the solid to aqueous transition. In Table 1, we identify and compare the bands in the Raman spectra of the aqueous $\mathrm{HIO}_{3}$ solution droplets and show they are consistent with Raman spectra of iodic acid solutions in the literature (Durig et al., 1965).

A selection of the spectra recorded when drying a deliquesced aqueous $\mathrm{HIO}_{3}$ droplet is shown in Fig. 3. Other droplets behaved in the same way. The most obvious change in the Raman spectra on reducing $\mathrm{RH}$ is that the $\mathrm{OH}$ bands at around $3400 \mathrm{~cm}^{-1}$ decreased in intensity as water evaporated from the droplets. Even though the water content was clearly reduced on drying and a supersaturated solution results, crystallisation did not occur and the droplet remained in an amorphous state in which water was retained. After leaving the droplet overnight at $0 \% \mathrm{RH}$, the droplet (or any other droplets) did not crystallise (Fig. 3e).

In the spectra at very low RH (Fig. 3c to e), the water signal around $3400 \mathrm{~cm}^{-1}$ appears to be distorted. The band at $3400 \mathrm{~cm}^{-1}$ is indicative of water molecules hydrogen bonded to other water molecules in a liquid environment, whereas the Raman signal from water molecules bound to a cation such as $\mathrm{H}_{3} \mathrm{O}^{+}$or $\mathrm{H}_{5} \mathrm{O}_{2}^{+}$forms a continuum on the low frequency side of the water band (Giguere and Guillot, 1982). The hydronium ion itself has a Raman signal which is orders of magnitude less in intensity than that of water (Giguere and Guillot, 1982). The continuum on the low frequency side of the $3400 \mathrm{~cm}^{-1}$ peak in Fig. $3 \mathrm{c}$ to e is consistent with many of the water molecules in this solution being protonated. 
Table 1. Assignment of bands in Raman spectra of aqueous $\mathrm{HIO}_{3}$ $\left(\mathrm{cm}^{-1}\right)$.

\begin{tabular}{lll}
\hline $\begin{array}{l}\text { This } \\
\text { Work }\end{array}$ & $\begin{array}{l}\text { 12 M Aqueous } \\
\text { Solution (Durig } \\
\text { et al., 1965) }\end{array}$ & Description \\
\hline 814 & 814 & \\
768 & 771 & $\mathrm{IO}_{2}\left(\mathrm{HO} \cdot \mathrm{IO}_{2}\right)$ assym. stretch \\
- & 737 & \\
\hline 644 & 638 & $\mathrm{IO}$ stretch \\
\hline 333 & 324 & $\mathrm{IO}_{2}$ deformation \\
\hline
\end{tabular}

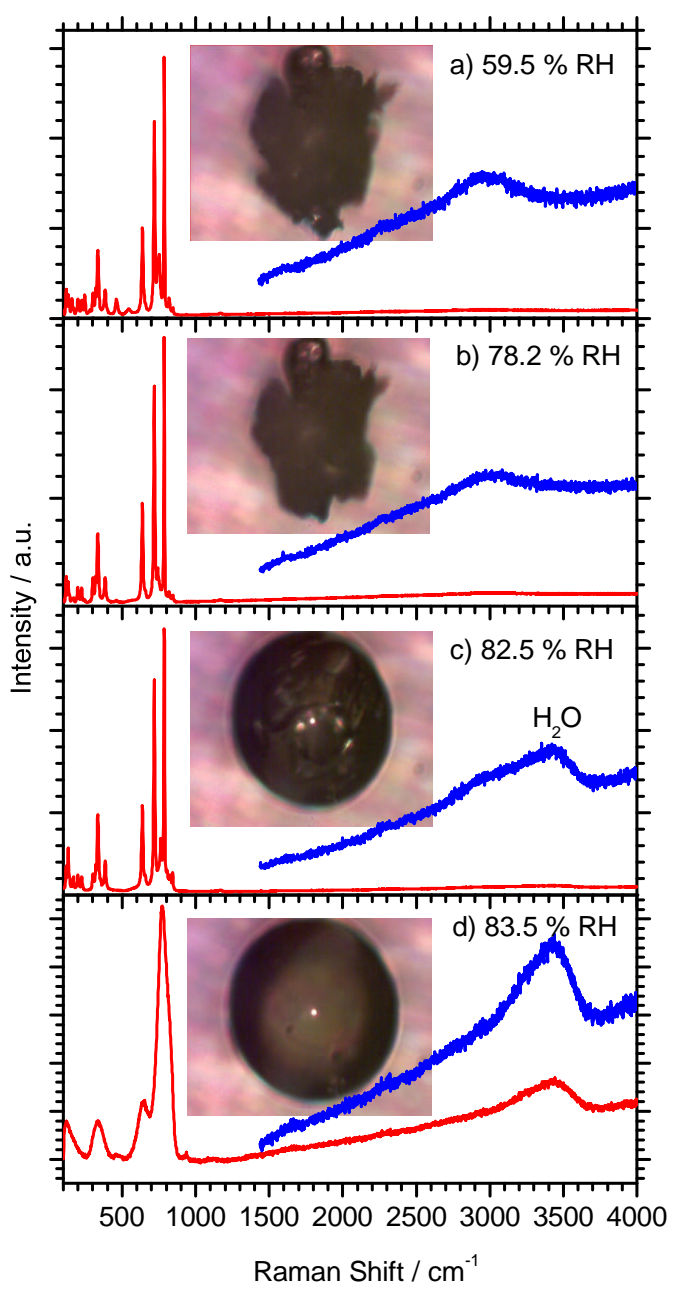

Fig. 2. Raman spectra of an initially crystalline $\mathrm{HIO}_{3}$ particle on increasing RH. The blue spectra are the region above $\sim 1500 \mathrm{~cm}^{-1}$ expanded for clarity. Deliquescence occurs around $82.5 \%$ RH (c-d) and is clearly evident in changes in both the image of the droplets and the Raman spectra. The width of the microscope images is $160 \mu \mathrm{m}$.

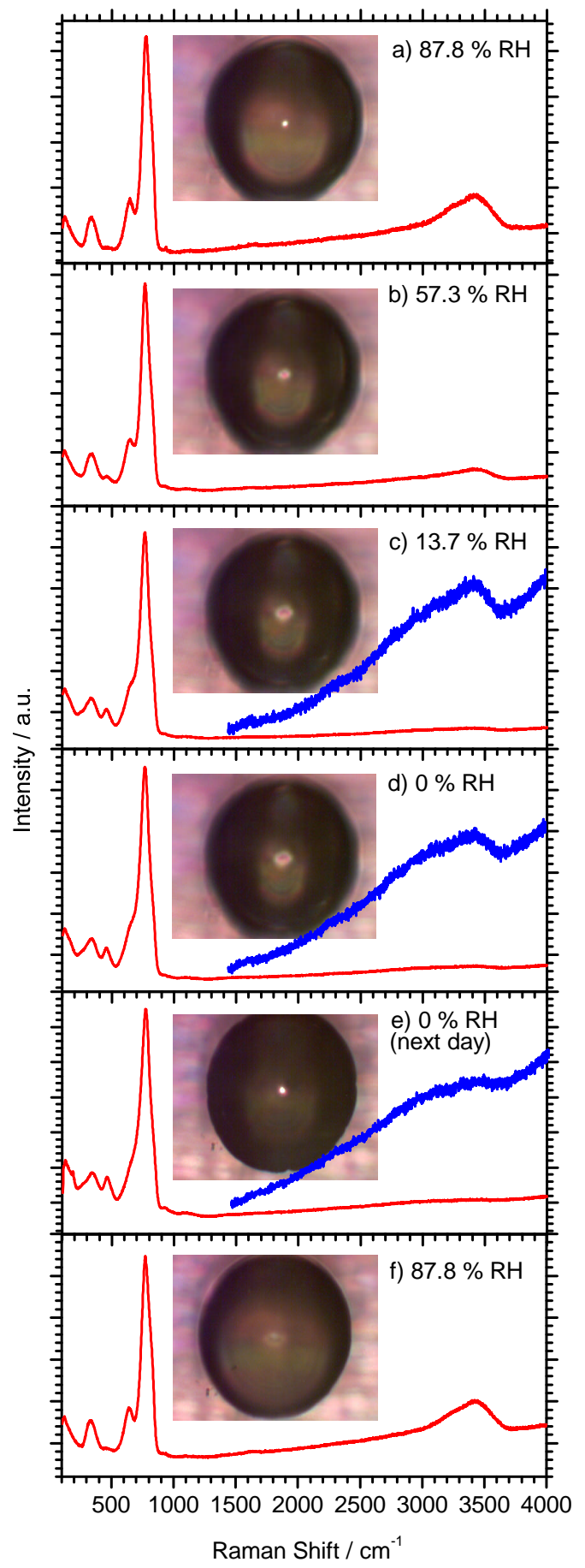

Fig. 3. Raman spectra of deliquesced $\mathrm{HIO}_{3}$ on decreasing $\mathrm{RH}$ (ad) and then increasing $\mathrm{RH}$ again on the following day (e-f) after leaving the droplets at $0 \% \mathrm{RH}$ overnight. The spectra are for the same droplet as in Fig. 2, but tests demonstrated that all droplets ( $\sim 30$ droplets) on the slide responded in a similar manner. The $\mathrm{OH}$ stretch band associated with water $\left(\sim 3400 \mathrm{~cm}^{-1}\right)$ decreases dramatically on reducing $\mathrm{RH}$, but the droplet does not revert back to its crystalline form. The blue expanded spectra are included only in cases where the $\mathrm{OH}$ band is weak. The width of the microscope images is $160 \mu \mathrm{m}$. 


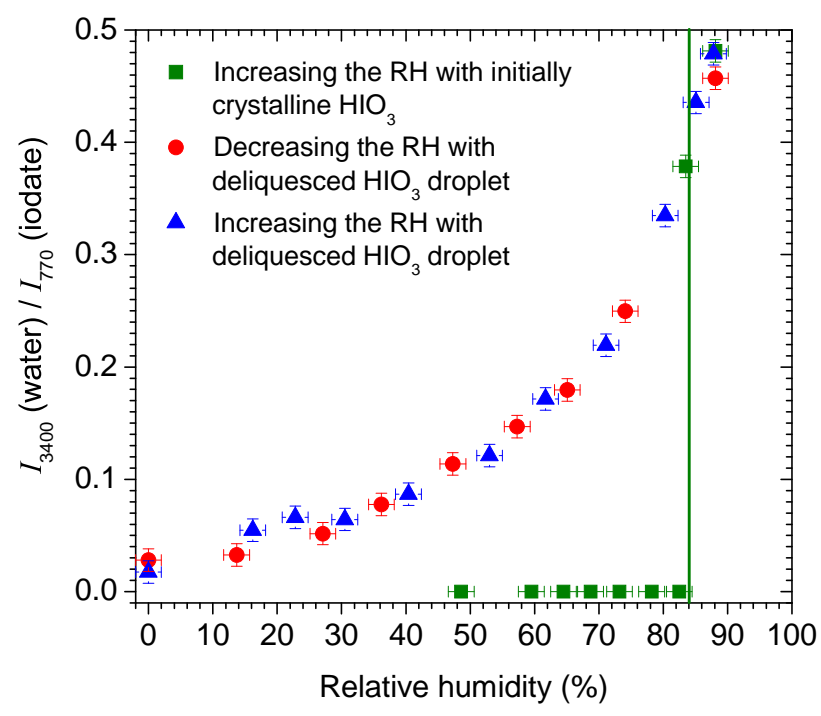

Fig. 4. Intensity ratio of peaks roughly centred at $3400 \mathrm{~cm}^{-1}\left(I_{3400}\right.$, $\mathrm{OH}$ stretch, i.e. water), and $770 \mathrm{~cm}^{-1}$ ( $I_{770}$, iodate) as a function of RH determined from spectra such as those shown in Fig. 2 and Fig. 3. The vertical green line indicates the expected deliquescence point (Kumar et al., 2010) and is in good agreement with the RH at which $\mathrm{HIO}_{3}$ clearly takes up water to become an aqueous liquid droplet. The estimated uncertainty on our RH measurement is $2 \%$. The intensities $I_{3400}$ and $I_{770}$ were determined by integrating the background subtracted signal between $2900-3800 \mathrm{~cm}^{-1}$ and 500 $1000 \mathrm{~cm}^{-1}$, respectively, for the liquid droplets. A value of zero was taken when the spectra were dominated by crystalline peaks (up to $82.5 \% \mathrm{RH}$ ). All these measurements were done with a single particle/droplet as the RH was initially increased around a dry crystalline particle until it had fully deliquesced (green), and then as the $\mathrm{RH}$ was reduced to $0 \% \mathrm{RH}$ (red), and then on the following day as it was increased again (blue).

On increasing the $\mathrm{RH}$, the intensity of the $\mathrm{OH}$ band increased again, further confirming that the droplet remained in a supersaturated aqueous state even at $0 \% \mathrm{RH}$ without a first order phase change (i.e. crystallisation) occurring. This spectroscopic information is summarised in Fig. 4 which shows the ratio of the integrated intensities of the $\mathrm{OH}$ stretch peak, indicative of water, centred at between 2900 and $3800 \mathrm{~cm}^{-1}$ and the iodate peaks between $500-1000 \mathrm{~cm}^{-1}$ as a function of $\mathrm{RH}$. This ratio is a measure of the amount of $\mathrm{H}_{2} \mathrm{O}$ hydrogen bonded to other $\mathrm{H}_{2} \mathrm{O}$ in the droplets rather than the total amount of water in the droplet (for the reasons discussed above). Nevertheless, this ratio is a useful measure of the water content as a function of RH. Figure 4 clearly shows that iodic acid solution droplets absorb and loose water in a reversible manner as RH is cycled and that even at $0 \% \mathrm{RH}$ a small, but significant, quantity of water remained in the droplets.

In order to probe the physical state of the droplets at low RH we applied a mechanical force to them. This involved pressing the flat end of a metal rod onto them by hand while

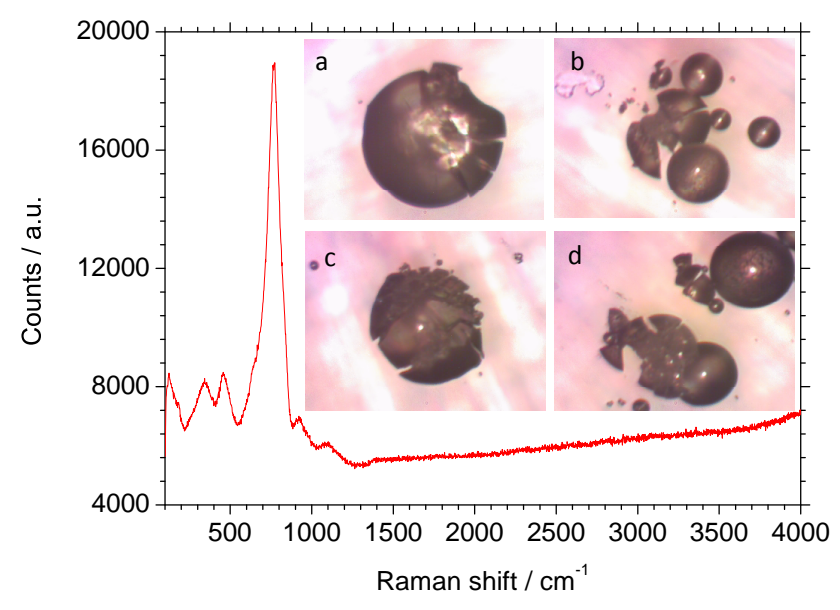

Fig. 5. Raman spectrum and images of "cracked" aqueous $\mathrm{HIO}_{3}$ droplets at $0 \% \mathrm{RH}$. For this test, deliquesced droplets were dried out to $0 \% \mathrm{RH}$ gradually over the course of $\sim 1.5 \mathrm{~h}$ and were then subjected to mechanical force using the flat end of a metal rod. The droplets shattered in much the same way as one would expect an ultra viscous liquid, such as pitch, or a brittle glass to shatter. The spectrum corresponds to (b). The width of the microscope images is $160 \mu \mathrm{m}$.

maintaining a flow of $\sim 0 \% \mathrm{RH}$ over the droplets. Images of the droplets in Fig. 5 reveal that many of the droplets shattered or cracked when subject to this mechanical force. These droplets behaved in a manner consistent with a glassy solid or an ultra-viscous liquid such as pitch. The effect of increasing RH on these cracked droplets is illustrated in Fig. 6. When the RH reaches about $16 \%$ RH the sharp edges begin to become rounded indicating increased mobility and at $18 \% \mathrm{RH}$ the individual fragments of droplets merged. This indicates that water serves as a plasticiser: i.e. as water is absorbed into the amorphous solid (or ultra-viscous liquid) it reduces its viscosity to the point where it behaves like a liquid with smaller fragments merging to form larger units.

These results may also provide an alternative explanation for growth factors well below unity for iodine oxide particles generated under dry conditions. Jimenez et al. (2003) and Saunders et al. (2010) observed a substantial reduction in the mobility diameter of the aerosol generated under dry conditions when exposed to $\mathrm{RH}$ of greater than $20 \% \mathrm{RH}$. Under dry conditions, the aerosol particles were shown to have fractal morphologies (Jimenez et al., 2003; Saunders and Plane, 2006) and it was suggested that water uptake into the capillaries would cause the fractals to collapse and form more dense particles (Saunders et al., 2010; McFiggans et al., 2004), hence resulting in an apparent growth factor of less than 1. An alternative explanation that is different in microphysical origin might be that the particles generated under dry conditions were amorphous solids. When the RH was increased, it is possible that water adsorbed and served as a plasticiser allowing the material to flow and coalesce 
$0 \% \mathrm{RH}$

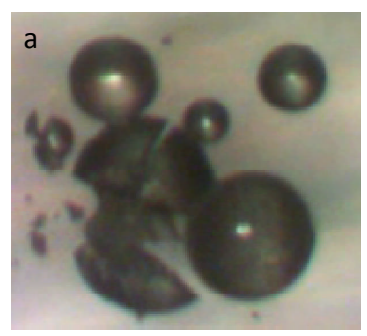

$18 \% \mathrm{RH}$

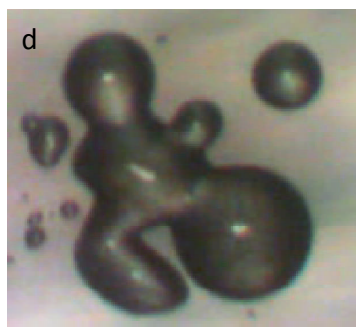

$10 \% \mathrm{RH}$

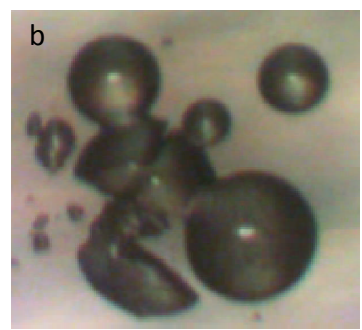

$20 \% \mathrm{RH}$

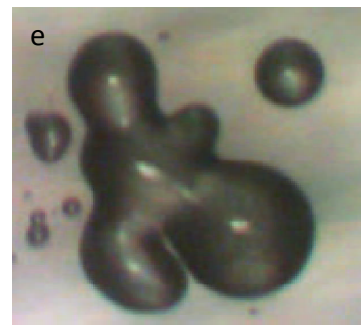

$16 \% \mathrm{RH}$

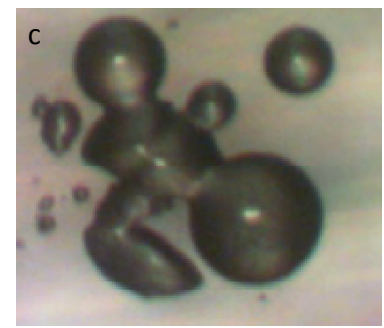

$25 \% \mathrm{RH}$

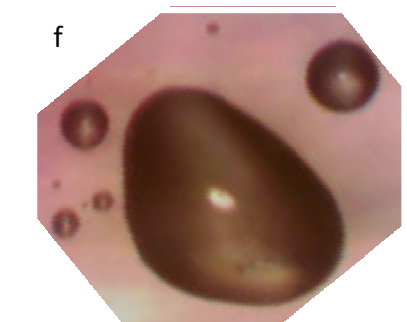

Fig. 6. Sequence of images of a cracked droplet gradually taking up water and flowing to reform a single droplet on increasing RH. (f) was taken with a different camera, hence the difference in orientation. The width of the microscope images is $160 \mu \mathrm{m}$. In these experiments the $\mathrm{RH}$ was ramped up to $18 \%$ over the course of $30 \mathrm{~min}$. It was then stepped up to $20 \%$ and held there for about 30 min and then stepped up to $25 \%$ where it was again held for about $20 \mathrm{~min}$.

into a more compact morphology in a similar manner to our cracked droplets which can be seen to flow on increasing $\mathrm{RH}$ in Fig. 6.

\subsection{Electrodynamic balance measurements of the rate of droplet evaporation}

The time-dependence of the size of an aqueous iodic acid droplet injected and trapped in dry nitrogen gas is shown in Fig. 7 as a function of time. These measurements were made with the concentric cylindrical electrode trap The initial evaporation of water from a droplet of initial size $21.5 \mu \mathrm{m}$ and a concentration of $50.4 \mathrm{~g} \mathrm{l}^{-1}$ occurs at a rate close to that of pure water (Fig. 7a). On approach to the dry size the evaporation rate decreases sharply at about $1.8 \mathrm{~s}$, consistent with formation of an amorphous solid state in which diffusion and evaporation is slow. Slow mass transfer is measured over $\sim 33 \mathrm{~h}$ (Fig. 7b) indicating that the droplets did not come to equilibrium during this period. Based on the density of crystalline iodic acid $\left(4.63 \mathrm{~g} \mathrm{~cm}^{-3}\right.$, Lide, 2009) and the density of the initial solution (Kumar et al., 2010), we estimate the dry size of the iodic acid particle to be $4.95 \pm 0.15 \mu \mathrm{m}$. In addition, a regular elastic scattering pattern persists at all times, even after $\sim 33 \mathrm{~h}$ (Fig. 7c), indicating sphericity is maintained throughout evaporation. The slow release of water over an extended period of time has been observed in glassy sucrose solutions (Tong et al., 2011; Zobrist et al., 2011); hence, these measurements are consistent with the iodic acid

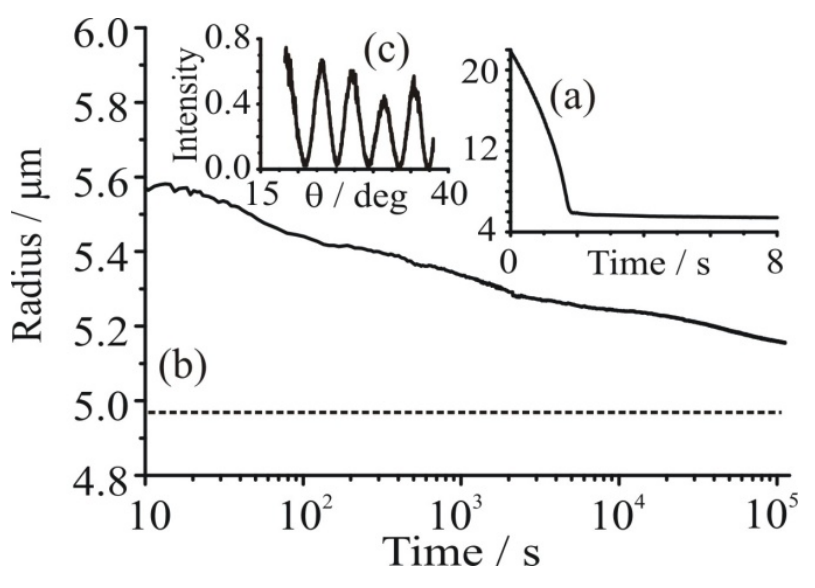

Fig. 7. (a) Initial loss of water on injection of a dilute aqueous $\mathrm{HIO}_{3}$ droplet into a dry atmosphere within the concentric cylindrical electrodynamic balance. The gray dashed horizontal line indicates the estimated dry size for a crystal of $\mathrm{HIO}_{3}(4.95 \pm 0.15 \mu \mathrm{m})$. (b) indicates the size decrease over $\sim 33 \mathrm{~h}$. (c) is a representative phase function observed after $70000 \mathrm{~s}$ indicating the droplet remained approximately spherical.

solution droplet existing in an amorphous solid state at very low humidity. 

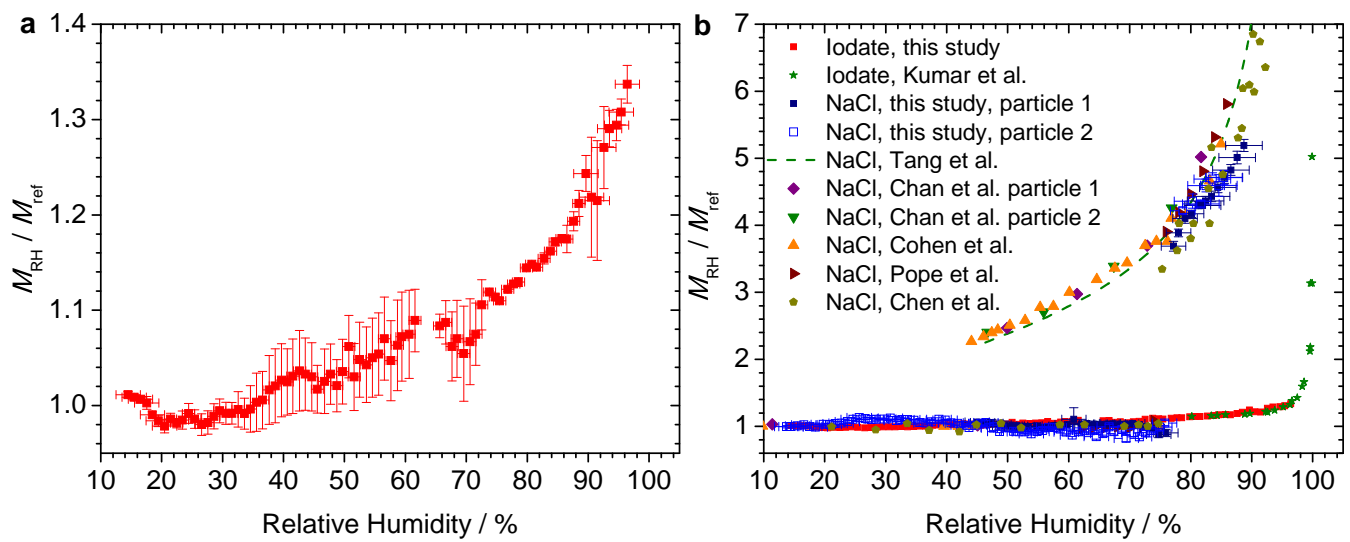

Fig. 8. Relative change in mass ( $\mathrm{GF}=$ mass growth factor $\left.=M_{\mathrm{RH}} / M_{\mathrm{ref}}\right)$ of droplets suspended in the electrodynamic balance on varying RH. (a) The relative change in mass of iodic acid solution droplets measured using the EDB, where $M_{\text {ref }}$ was chosen as an average of points below $20 \%$ RH. Note that even at low RH, iodic acid droplets contain a significant amount of water; see Fig. 9. (b) The same iodic acid data is plotted (also in red) and compared with the growth of sodium chloride. Our measurements of NaCl hygroscopic growth are compared to literature data (Chan et al., 1997; Cohen et al., 1987; Pope et al., 2010; Chen et al., 2003; Tang et al., 1997). In addition we plot the GF corresponding to water activity literature data for bulk iodic acid solutions of known concentration in green circles (Kumar et al., 2010); the translation from concentration $(C)$ in wt \% of solute to growth factor here requires some explanation. In order to translate concentration into GF we need to relate the data at an RH where the composition is well known. We chose a point close to the deliquescence point where we are confident that the solution is in equilibrium with the surrounding vapour, rather than at a low RH where the iodic acid droplets become ultra-viscous or glassy (see discussion in text). Hence, $\mathrm{GF}_{\mathrm{RH}}=\mathrm{GF}^{*} C^{*} / C_{\mathrm{RH}}$ and we chose $83.8 \%$ as $\mathrm{RH}^{*}$ at which $\mathrm{RH}$ the EDB gives a $\mathrm{GF}^{*}$ of 1.16. According to Kumar et al. (2010) the corresponding $C^{*}$ is $75.32 \mathrm{wt} \%$, which then allows us to translate Kumar et al.'s data into GF (green points).

\subsection{Electrodynamic balance measurements of hygroscopic growth}

The relative mass growth curve for an iodic acid solution droplet is shown in Fig. 8a and is defined as ratio of mass at a $\mathrm{RH}$ to the mass at a reference $\mathrm{RH}\left(M_{\mathrm{RH}} / M_{\text {ref }}\right.$, where $M_{\text {ref }}$ is an average of points below $\left.20 \% \mathrm{RH}\right)$. Note that $M_{\text {ref }}$ is not the mass for a dry particle when the solution forms a glass at low $\mathrm{RH}$. The relative mass growth is only about $20 \%$ on increasing the RH from below $15 \%$ to $90 \%$. This is a remarkably small uptake of water for a species that is highly soluble in water $(0.26$ moles per mole of water or $308 \mathrm{~g} / 100 \mathrm{~g}$ of water at $25^{\circ} \mathrm{C}$, Lide, 2009). This small GF is consistent with a non-peer reviewed measurement of nebulised iodic acid droplets (Ristovski et al., 2006). The mass of an aqueous sodium chloride particle, for example, increases by about $700 \%$ on increasing the RH to $90 \%$ from $0 \%$ (see Fig. 8b). We can estimate the diameter growth of the iodic acid solution droplet if we assume that the density of supersaturated iodic acid solutions does not change over this range: a $20 \%$ change in mass would correspond to an increase in diameter of only $6 \%$. This value is consistent with the small diameter growth factors observed for particles generated under humid conditions in the laboratory (Jimenez et al., 2003; McFiggans et al., 2004). We suggest that the hygroscopic growth measurements in previous laboratory studies of iodine oxide particles are consistent with the aerosol being composed of aqueous iodic acid solutions. The growth factor information alone does not rule out the possibility that those iodine oxide particles were $\mathrm{I}_{2} \mathrm{O}_{4}$. However, given that the elemental composition measurements of laboratory generated material indicate an $\mathrm{I}_{2} \mathrm{O}_{5}$ composition (the anhydrous crystalline form of iodic acid) (Saunders and Plane, 2005), it is likely that the material generated in those previous experiments was iodic acid if there was sufficient water present or $\mathrm{I}_{2} \mathrm{O}_{5}$ if generated under very dry conditions. These experimental studies also suggest that the nucleation mode particles initially produced in the marine boundary layer are composed of iodic acid. Given the humid conditions there it will always be in an aqueous liquid state, which would facilitate uptake of other condensable materials.

The reason why iodic acid solution droplets should have a weak growth compared to other soluble salts is unclear. In solution, iodic acid is thought to form polymeric structures which lead to strongly non-ideal properties (Goldman et al., 1974; Ivanov et al., 1985). It has been suggested that the formation of polymers of iodic acid with bound water may also be responsible for glass formation in concentrated solutions (Ivanov et al., 1985). Hence, the formation of polymers may be related to the very strong dependence of water activity on solute concentration and its unusual hygroscopic growth. $\mathrm{MgSO}_{4}$ is also known to form polymeric structures in concentrated solutions and water transfer into and out of concentrated $\mathrm{MgSO}_{4}$ solutions is retarded when it forms an 

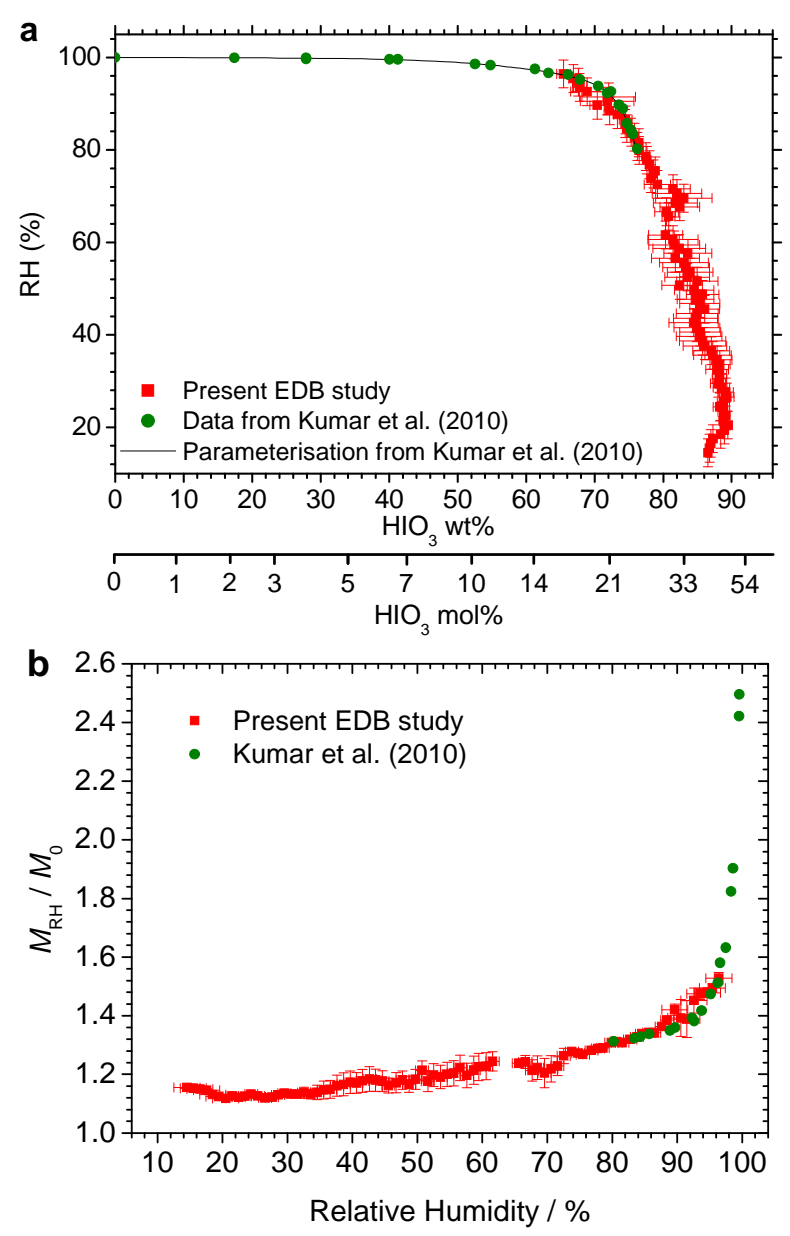

Fig. 9. (a) Variation of solute mass concentration as a function of RH. Direct measurements of water activity of solutions of known composition were taken from Kumar et al. (2010) and the data for lower RH was determined using the measured EDB growth factor. The growth factor data were translated into concentration by relating the data at $83.8 \% \mathrm{RH}$ where the concentration is well known. We use the formula (rearranged from the caption to Fig. 8): $C_{\mathrm{RH}}=$ $C^{*} \mathrm{GF}^{*} / \mathrm{GF}_{\mathrm{RH}}$, where $C^{*}=75.32 \%$ and $\mathrm{GF}^{*}=1.16$. We have not been able to find a satisfactory empirical fit to describe this data, instead the data is included as supporting material ("wt \%_vs_RH.cvs" and "EDB_RH_vs_GF.cvs"). (b) The same data as in (a), but presented as $M_{\mathrm{RH}} / M_{0}$, where $M_{0}$ is the mass of the dry iodic acid $\left(\mathrm{HIO}_{3}\right)$. This is the growth factor referenced to the dry mass $\left(\mathrm{GF}_{0}\right)$ rather than the observed mass at low RH in Fig. 8a. Note that the $\mathrm{GF}_{0}$ does not tend to 1.0 , but remains at a higher value due to retained water in the ultra-viscous or glassy droplets.

amorphous solid at low RH (Li et al., 2011; Zhang and Chan, 2000), although aqueous $\mathrm{MgSO}_{4}$ droplets differ from $\mathrm{HIO}_{3}$ droplets in that they still grow substantially on increasing $\mathrm{RH}$ to $90 \%$ (Tang et al., 1997; Zhang and Chan, 2000). Further work is needed to understand the role of polymerisation in aqueous $\mathrm{HIO}_{3}$, as well as other atmospherically relevant solutions, and its influence on hygroscopic properties.
In Fig. 9a we have translated the EDB mass growth data into concentration and compared the results with the direct measurements of water activity and solute concentration previously reported by Kumar et al. (2010). The concentration $(C)$ is related to the growth factor through the formula: $C_{\mathrm{RH}}=C^{*} \mathrm{GF}^{*} / \mathrm{GF}_{\mathrm{RH}}$, but the choice of $\mathrm{RH}$ at which to relate $C$ and $\mathrm{GF}$ requires some consideration. For solutions such as aqueous $\mathrm{NaCl}$, which crystallise to an anhydrous salt on drying, it is appropriate to determine the mass fraction from growth factor data making the assumption that on approaching $0 \% \mathrm{RH}$, the mass fraction of solute is 1.0 . However, this assumption is not appropriate for many materials. For example Peng et al. (2001) showed that at $5 \%$ RH, citric acid, malic acid and tartaric acid retained between 5 and $10 \%$ water, i.e. the mass fraction does not tend to 1.0. Cohen et al. (1987) report that $\mathrm{CaCl}_{2}$ retains about $40 \mathrm{wt} \%$ water when at $10 \% \mathrm{RH}$, which is equivalent to 4 moles of water for every mole of $\mathrm{CaCl}_{2}$. Similarly they found $\mathrm{MnSO}_{4}$ to retain about $30 \%$ water. Cohen et al. (1987) suggest that these materials may have formed a glass or a gel at low RH. More recently, it has been shown that the kinetics of water loss in sucrose solutions are slow at low humidity and it should therefore not be assumed that aqueous droplets are at equilibrium at low RH (Tong et al., 2011; Zobrist et al., 2011). Indeed, there has been an on-going debate about the reliability of using the "dry" state as a reference point; a much more reliable choice is to use an $\mathrm{RH}$ corresponding to the saturation concentration of the solute, equivalent to the deliquescence point (Reid et al., 2007; Krieger et al., 2012). Since we know that iodic acid droplets form an ultra-viscous liquid or glass at low RH and most likely retains water (reinforced by the fast measurements of water release: Fig. 7), we relate our data at a point close to the deliquescence $\mathrm{RH}$ for $\mathrm{HIO}_{3}$. At this $\mathrm{RH}$, the solution droplets are unambiguously in equilibrium (i.e. water activity $=\mathrm{RH}$ ) and water activity measurements are in excellent agreement with deliquescence measurements (Kumar et al., 2010). We have chosen to relate the data sets at $83.8 \%$ RH where the EDB measured $\mathrm{GF}^{*}$ was 1.16 and according to Kumar et al. (2010) $C^{*}=75.32 \mathrm{wt} \%$.

The resulting variation of solute concentration with $\mathrm{RH}$ is shown in Fig. 9a. In the RH range where the bulk water activity data (Kumar et al., 2010) and present EDB data sets overlap they are in agreement within experimental uncertainty. In addition, the general trend at lower RH is also consistent with the previous bulk measurements. This indicates that the droplets retain $\sim 13 \pm 3 \mathrm{wt} \%$ water (i.e. $87 \pm 3 \mathrm{wt} \%$ $\mathrm{HIO}_{3}$ ) at low RH, consistent with water retention in an amorphous solid or semi-solid state. The retention of water in iodic acid solutions has been reported in the past by Ivanov et al. (1984) who estimated that iodic acid solutions of $83 \mathrm{wt} \%$ $\mathrm{HIO}_{3}\left(17 \mathrm{wt} \% \mathrm{H}_{2} \mathrm{O}\right)$ were glassy, which is very close to our value. The presence of water in iodic acid droplets is corroborated by the distorted $\mathrm{OH}$ peak in the Raman spectra (Fig. 3). The general trend of increasing mass with increasing $\mathrm{RH}$ is reflected in the increase in $\mathrm{OH}$ stretch signal in the Raman 
study (Fig. 4), hence the Raman spectra and EDB results are in qualitative agreement.

Using the data in Fig. 9a we have determined the growth factor relative to the dry $\mathrm{HIO}_{3}$ mass $\left(\mathrm{GF}_{0}=M_{\mathrm{RH}} / M_{0}\right.$, where $M_{0}$ is the dry mass). At low $\mathrm{RH}, \mathrm{GF}_{0}$ remains significantly above 1.0 due to retained water in the ultra-viscous or glassy droplet. This emphasises the pitfalls associated with assuming that droplets contain negligible water at low $\mathrm{RH}$, as is often done (Krieger et al., 2012).

The physical state of iodine oxide particles most likely influences their growth. Saunders et al. (2010) show that the uptake coefficient of $\mathrm{H}_{2} \mathrm{SO}_{4}$ on iodic acid particles decreases dramatically at low RH (their Fig. 13). This is consistent with the formation of an amorphous solid or semi-solid at below $\sim 15 \% \mathrm{RH}$ in which the diffusion of $\mathrm{H}_{2} \mathrm{SO}_{4}$ into the particles is kinetically limited. This will not be a limitation to growth in the marine boundary layer where the humidity is such that the accommodation coefficient is around 0.7, but does help us to understand these laboratory measurements (Saunders et al., 2010).

\section{Summary and conclusions}

Our laboratory experiments show that iodic acid solution droplets have a very low propensity to crystallise on drying to low RH. Instead they form an amorphous solid or semisolid state which retains significant amounts of water. The hygroscopic growth of iodic acid solution droplets is very small, which is surprising considering $\mathrm{HIO}_{3}$ and $\mathrm{I}_{2} \mathrm{O}_{5}$ are highly soluble. Such droplets grow by only $20 \%$ between 20 and $90 \% \mathrm{RH}$ and we determine the hygroscopicity parameter $(\kappa)$, as defined by Petters and Kreidenweis (2007), for iodic acid droplets is 0.024 . This value is within the range commonly associated with weakly soluble organic materials and secondary organic aerosol particles (Petters and Kreidenweis, 2007). Hygroscopicity parameter values for highly soluble inorganic species normally fall in the range of 0.5 to 1.4. Iodine oxide particles generated in laboratory experiments also have very small growth factors. This has led previous authors to conclude that iodine oxide particles must be insoluble and they went on to suggest the composition of iodine oxide particles was the insoluble $\mathrm{I}_{2} \mathrm{O}_{4}$ rather than the highly soluble $\mathrm{I}_{2} \mathrm{O}_{5}$ or $\mathrm{HIO}_{3}$ (Jimenez et al., 2003). Here we have shown that the very small hygroscopic growth factors of laboratory generated particles are consistent with these aerosol particles being composed of aqueous iodic acid. We also suggest that the initially formed nucleation mode particles, which are thought to be composed of iodine oxides, in the marine boundary layer are composed of aqueous iodic acid. Under the humid conditions of the marine boundary layer, these droplets will exist in a liquid state which will facilitate their uptake of $\mathrm{H}_{2} \mathrm{SO}_{4}$. However, the retention of water at low $\mathrm{RH}$, due to the formation of amorphous solid or semi-solid states, must be taken into consideration when interpreting hygroscopic growth measurements.

\section{Supplementary material related to this article is available online at: http://www.atmos-chem-phys.net/12/ 8575/2012/acp-12-8575-2012-supplement.zip.}

Acknowledgements. We thank Tony Windross (University of Leeds) for his assistance in constructing the Raman Microscope humidity controlled stage. The European Research Council (ERC) supported BJM through a Starting Grant (FP7, 240449 ICE) and funded the Raman microscope experiments as well as funding HCP's PhD studentship. DOS acknowledges the UK Natural Environment Research Council (NERC, NE/I013466/1). NSU thanks the Nigerian Niger Delta Development Commission (NDDC/DEHSS/2010PGFS/AK/011) for financial assistance in his PhD studies and SP thanks NERC (NE/H021108/1) for post-doctoral funding. JPR acknowledges financial support from the UK Engineering and Physical Science Research Council (EPSRC) through the support of a Leadership Fellowship and JFD acknowledges the EPSRC for postgraduate studentship funding. AEH acknowledges the University of Bristol for the support of a post-doctoral research fellowship. RK is grateful to the Indian Government for PhD funding, and Multanimal Modi (Postgraduate) College, Modinagar (U.P.), India for granting study leave. RWS acknowledges partial funding for this work from the NERC (NE/E005659/1).

Edited by: T. Koop

\section{References}

Angell, C. A.: Liquid fragility and the glass transition in water and aqueous solutions, Chem. Rev., 102, 2627-2650, 2002.

Bodsworth, A., Zobrist, B., and Bertram, A. K.: Inhibition of efflorescence in mixed organic-inorganic particles at temperatures less than 250 k, Phys. Chem. Chem. Phys., 12, 12259-12266, doi:10.1039/c0cp00572j, 2010.

Broadley, S. L., Murray, B. J., Herbert, R. J., Atkinson, J. D., Dobbie, S., Malkin, T. L., Condliffe, E., and Neve, L.: Immersion mode heterogeneous ice nucleation by an illite rich powder representative of atmospheric mineral dust, Atmos. Chem. Phys., 12, 287-307, doi:10.5194/acp-12-287-2012, 2012.

Chan, C. K., Kwok, C. S., and Chow, A. H. L.: Study of hygroscopic properties of aqueous mixtures of disodium fluorescein and sodium chloride using an electrodynamic balance, Pharmaceutical Research, 14, 1171-1175, doi:10.1023/a:1012146621821, 1997.

Chan, C. K., Flagan, R. C., and Seinfeld, J. H.: In situ study of single aqueous droplet solidification of ceramic precursors used for spray pyrolysis, J. Am. Ceram. Soc., 81, 646-648, 1998.

Chen, L. Y., Jeng, F. T., Chen, C. C., and Hsiao, T. C.: Hygroscopic behavior of atmospheric aerosol in taipei, Atmos. Environ., 37, 2069-2075, doi:10.1016/S1352-2310(03)00071-2, 2003.

Cohen, M. D., Flagan, R. C., and Seinfeld, J. H.: Studies of concentrated electrolyte-solutions using the electrodynamic balance .1 . Water activities for single-electrolyte solutions, J. Phys. Chem., 91, 4563-4574, doi:10.1021/j100301a029, 1987. 
Daehlie, G. and Kjekshus, A.: Iodine oxides:Part i. On $\mathrm{I}_{2} \mathrm{O}_{3} \cdot \mathrm{SO}_{3}$, $\mathrm{I}_{2} \mathrm{O}_{3} \cdot 4 \mathrm{SO}_{3} \cdot \mathrm{H}_{2} \mathrm{O}, \mathrm{I}_{2} \mathrm{O}_{3} \cdot \mathrm{SeO}_{3}$ and $\mathrm{I}_{2} \mathrm{O}_{4}$, Acta Chem. Scan., 18, 144-156, 1964.

Davies, J. F., Haddrell, A. E., and Reid, J. P.: Time-resolved measurements of the evaporation of volatile components from single aerosol droplets, Aerosol Sci. Tech., 46, 666-677, doi:10.1080/02786826.2011.652750, 2012.

Durig, J. R., Bonner, O. D., and Breazeale, W. H.: Raman studies of iodic acid and sodium iodate, J. Phys. Chem., 69, 3886-3892, doi:10.1021/j100895a041, 1965.

Dymarska, M., Murray, B. J., Sun, L. M., Eastwood, M. L., Knopf, D. A., and Bertram, A. K.: Deposition ice nucleation on soot at temperatures relevant for the lower troposphere, J. Geophys. Res.-Atmos., 111, D04204, doi:10.1029/2005JD006627, 2006.

Edgeworth, R., Dalton, B. J., and Parnell, T.: The pitch drop experiment, Eur. J. Phys, 5, 198-200, 1984.

Giguere, P. A. and Guillot, J. G.: Raman spectrum of hydronium $\left(\mathrm{H}_{3} \mathrm{O}^{+}\right)$ions in aqueous acids, J. Phys. Chem., 86, 3231-3233, doi:10.1021/j100213a031, 1982.

Glantschnig, W. J. and Chen, S.-H.: Light scattering from water droplets in the geometrical optics approximation, Appl. Opt., 20, 2499-2509, 1981.

Goldman, S., Bates, R. G., and Robinson, R. A.: Osmotic coefficients and activity coefficients of iodic acid at high concentrations, J. Solution Chem., 3, 593-602, 1974.

Hargreaves, G., Kwamena, N. O. A., Zhang, Y. H., Butler, J. R., Rushworth, S., Clegg, S. L., and Reid, J. P.: Measurements of the equilibrium size of supersaturated aqueous sodium chloride droplets at low relative humidity using aerosol optical tweezers and an electrodynamic balance, J. Phys. Chem. A, 114, 18061815, doi:10.1021/jp9095985, 2010.

Ivanov, A. A., Kirilenko, I. A., Azarova, L. A., and Vinogradov, E. E.: The electrical conductivities of solutions of the glass forming system $\mathrm{HIO}_{3}-\mathrm{H}_{2} \mathrm{O}$, Russian Journal of Inorganic Chemistry, 29, 1209-1211, 1984.

Ivanov, A. A., Kirilenko, I. A., Azarova, L. A., and Vinogradov, E. E.: Properties and structure of solutions in the $\mathrm{HIO}_{3}-\mathrm{H}_{2} \mathrm{O}$ glass forming system, Russian Journal of Inorganic Chemistry, 30, 603-605, 1985.

Jimenez, J. L., Bahreini, R., Cocker, D. R., Zhuang, H., Varutbangkul, V., Flagan, R. C., Seinfeld, J. H., O’Dowd, C. D., and Hoffmann, T.: New particle formation from photooxidation of diiodomethane $\left(\mathrm{CH}_{2} \mathrm{I}_{2}\right)$, J. Geophys. Res.-Atmos., 108, 4318, doi:10.1029/2002jd002452, 2003.

Knopf, D. A. and Lopez, M. D.: Homogeneous ice freezing temperatures and ice nucleation rates of aqueous ammonium sulfate and aqueous levoglucosan particles for relevant atmospheric conditions, Phys. Chem. Chem. Phys., 11, 8056-8068, doi:10.1039/b903750k, 2009.

Koop, T., Ng, H. P., Molina, L. T., and Molina, M. J.: A new optical technique to study aerosol phase transitions: The nucleation of ice from h2so4 aerosols, J. Phys. Chem. A, 102, 8924-8931, doi:10.1021/jp9828078, 1998.

Koop, T., Bookhold, J., Shiraiwa, M., and Pöschl, U.: Glass transition and phase state of organic compounds: Dependency on molecular properties and implications for secondary organic aerosols in the atmosphere, Phys. Chem. Chem. Phys., 13, 19238-19255, doi:10.1039/c1cp22617g, 2011.
Krieger, U. K., Marcolli, C., and Reid, J. P.: Exploring the complexity of aerosol particle properties and processes using single particle techniques, Chemical Society Reviews, 41, 6631-6662, doi:10.1039/C2CS35082C, 2012.

Kumar, R., Saunders, R. W., Mahajan, A. S., Plane, J. M. C., and Murray, B. J.: Physical properties of iodate solutions and the deliquescence of crystalline $\mathrm{I}_{2} \mathrm{O}_{5}$ and $\mathrm{HIO}_{3}$, Atmos. Chem. Phys., 10, 12251-12260, doi:10.5194/acp-10-12251-2010, 2010.

Li, K.-K., Wang, F., Zeng, G., Reid, J. P., and Zhang, Y.-H.: Probing the time scale for bulk equilibration and mass transport of water in amorphous inorganic aerosol, J. Phys. Chem. B, 115, 1439714403, doi:10.1021/jp209379f, 2011.

Lide, D. R.: Crc handbook of chemistry and physics, 90th ed., CRC, Boca Raton, Fla.; London, 2009.

Mahajan, A. S., Plane, J. M. C., Oetjen, H., Mendes, L., Saunders, R. W., Saiz-Lopez, A., Jones, C. E., Carpenter, L. J., and McFiggans, G. B.: Measurement and modelling of tropospheric reactive halogen species over the tropical Atlantic Ocean, Atmos. Chem. Phys., 10, 4611-4624, doi:10.5194/acp-10-4611-2010, 2010.

Mäkelä, J. M., Hoffmann, T., Holzke, C., Vakeva, M., Suni, T., Mattila, T., Aalto, P. P., Tapper, U., Kauppinen, E. I., and O'Dowd, C. D.: Biogenic iodine emissions and identification of end-products in coastal ultrafine particles during nucleation bursts, J. Geophys. Res.-Atmos., 107, 8110, doi:10.1029/2001jd000580, 2002.

Martin, S. T.: Phase transitions of aqueous atmospheric particles, Chem. Rev., 100, 3403-3453, doi:10.1021/cr990034t, 2000.

McFiggans, G., Coe, H., Burgess, R., Allan, J., Cubison, M., Alfarra, M. R., Saunders, R., Saiz-Lopez, A., Plane, J. M. C., Wevill, D., Carpenter, L., Rickard, A. R., and Monks, P. S.: Direct evidence for coastal iodine particles from Laminaria macroalgae - linkage to emissions of molecular iodine, Atmos. Chem. Phys., 4, 701-713, doi:10.5194/acp-4-701-2004, 2004.

McFiggans, G., Bale, C. S. E., Ball, S. M., Beames, J. M., Bloss, W. J., Carpenter, L. J., Dorsey, J., Dunk, R., Flynn, M. J., Furneaux, K. L., Gallagher, M. W., Heard, D. E., Hollingsworth, A. M., Hornsby, K., Ingham, T., Jones, C. E., Jones, R. L., Kramer, L. J., Langridge, J. M., Leblanc, C., LeCrane, J.-P., Lee, J. D., Leigh, R. J., Longley, I., Mahajan, A. S., Monks, P. S., Oetjen, H., Orr-Ewing, A. J., Plane, J. M. C., Potin, P., Shillings, A. J. L., Thomas, F., von Glasow, R., Wada, R., Whalley, L. K., and Whitehead, J. D.: Iodine-mediated coastal particle formation: an overview of the Reactive Halogens in the Marine Boundary Layer (RHaMBLe) Roscoff coastal study, Atmos. Chem. Phys., 10, 2975-2999, doi:10.5194/acp-10-2975-2010, 2010.

Mikhailov, E., Vlasenko, S., Martin, S. T., Koop, T., and Pöschl, U.: Amorphous and crystalline aerosol particles interacting with water vapor: conceptual framework and experimental evidence for restructuring, phase transitions and kinetic limitations, Atmos. Chem. Phys., 9, 9491-9522, doi:10.5194/acp-9-9491-2009, 2009.

Murphy, D. M. and Koop, T.: Review of the vapour pressures of ice and supercooled water for atmospheric applications, Q. J. Roy. Meteor. Soc., 131, 1539-1565, 2005.

Murray, B. J.: Inhibition of ice crystallisation in highly viscous aqueous organic acid droplets, Atmos. Chem. Phys., 8, 54235433, doi:10.5194/acp-8-5423-2008, 2008.

Murray, B. J. and Bertram, A. K.: Strong dependence of cubic ice formation on droplet ammonium to sulfate ratio, Geophys. Res. Lett., 34, L16810, doi:10.1029/2007GL030471, 2007. 
Murray, B. J. and Bertram, A. K.: Inhibition of solute crystallisation in aqueous $\mathrm{H}^{+}-\mathrm{NH}_{4}{ }^{+}-\mathrm{SO}_{4}^{2-}-\mathrm{H}_{2} \mathrm{O}$ droplets, Phys. Chem. Chem. Phys., 10, 3287-3301, doi:10.1039/b802216j, 2008.

Murray, B. J., Broadley, S. L., Wilson, T. W., Bull, S. J., Wills, R. H., Christenson, H. K., and Murray, E. J.: Kinetics of the homogeneous freezing of water, Phys. Chem. Chem. Phys., 12, 1038010387, doi:10.1039/c003297b, 2010a.

Murray, B. J., Wilson, T. W., Dobbie, S., Cui, Z., Al-Jumur, S. M. R. K., Mohler, O., Schnaiter, M., Wagner, R., Benz, S., Niemand, M., Saathoff, H., Ebert, V., Wagner, S., and Karcher, B.: Heterogeneous nucleation of ice particles on glassy aerosols under cirrus conditions, Nature Geosci., 3, 233-237, 2010 b.

Murray, B. J., Broadley, S. L., and Morris, G. J.: Supercooling of water droplets in jet aviation fuel, Fuel, 90, 433-435, 2011 a.

Murray, B. J., Broadley, S. L., Wilson, T. W., Atkinson, J. D., and Wills, R. H.: Heterogeneous freezing of water droplets containing kaolinite particles, Atmos. Chem. Phys., 11, 4191-4207, doi:10.5194/acp-11-4191-2011, 2011 b.

O’Dowd, C. D. and De Leeuw, G.: Marine aerosol production: A review of the current knowledge, Philos. T. Royal Soc. a, 365, 1753-1774, doi:10.1098/rsta.2007.2043, 2007.

O'Dowd, C. D. and Hoffmann, T.: Coastal new particle formation: A review of the current state-of-the-art, Environ. Chem., 2, 245255, doi:10.1071/en05077, 2005.

Onasch, T. B., Siefert, R. L., Brooks, S. D., Prenni, A. J., Murray, B., Wilson, M. A., and Tolbert, M. A.: Infrared spectroscopic study of the deliquescence and efflorescence of ammonium sulfate aerosol as a function of temperature, J. Geophys. Res.-Atmos., 104, 21317-21326, 1999.

Pant, A., Parsons, M. T., and Bertram, A. K.: Crystallization of aqueous ammonium sulfate particles internally mixed with soot and kaolinite: Crystallization relative humidities and nucleation rates, J. Phys. Chem. A, 110, 8701-8709, doi:10.1021/jp060985s, 2006.

Peng, C., Chan, M. N., and Chan, C. K.: The hygroscopic properties of dicarboxylic and multifunctional acids: Measurements and unifac predictions, Environ. Sci. Technol., 35, 4495-4501, doi:10.1021/es0107531, 2001.

Petters, M. D. and Kreidenweis, S. M.: A single parameter representation of hygroscopic growth and cloud condensation nucleus activity, Atmos. Chem. Phys., 7, 1961-1971, doi:10.5194/acp-71961-2007, 2007.

Pope, F. D., Tong, H.-J., Dennis-Smither, B. J., Griffiths, P. T., Clegg, S. L., Reid, J. P., and Cox, R. A.: Studies of single aerosol particles containing malonic acid, glutaric acid, and their mixtures with sodium chloride. Ii. Liquid-state vapor pressures of the acids, J. Phys. Chem. A, 114, 10156-10165, doi:10.1021/jp1052979, 2010.

Reid, J. P., Meresman, H., Mitchem, L., and Symes, R.: Spectroscopic studies of the size and composition of single aerosol droplets, Int. Rev. Phys. Chem., 26, 139-192, doi:10.1080/01442350601081899, 2007.

Ristovski, Z. D., Fletcher, C., D’Anna, B., Johnson, G. R., and Bostrom, J. T.: Characterization of iodine particles with Volatilization-Humidification Tandem Differential Mobility Analyser (VH-TDMA), Raman and SEM techniques, Atmos. Chem. Phys. Discuss., 6, 1481-1508, doi:10.5194/acpd-6-14812006, 2006.
Saiz-Lopez, A., Plane, J. M. C., Baker, A. R., Carpenter, L. J., von Glasow, R., Gomez Martín, J. C., McFiggans, G., and Saunders, R. W.: Atmospheric chemistry of iodine, Chem. Rev., 112, 17731804, doi:10.1021/cr200029u, 2011.

Saunders, R. W. and Plane, J. M. C.: Formation pathways and composition of iodine oxide ultra-fine particles, Environ. Chem., 2, 299-303, doi:10.1071/en05079, 2005.

Saunders, R. W. and Plane, J. M. C.: Fractal growth modelling of $\mathrm{I}_{2} \mathrm{O}_{5}$ nanoparticles, J. Aerosol Sci., 37, 1737-1749, doi:10.1016/j.jaerosci.2006.08.007, 2006.

Saunders, R. W., Kumar, R., Gomez Martin, J. C., Mahajan, A. S., Murray, B. J., and Plane, J. M. C.: Studies of the formation and growth of aerosol from molecular iodine precursor, Zeitschrift Fur Physikalische Chemie-International Journal of Research in Physical Chemistry \& Chemical Physics, 224, 10951117, doi:10.1524/zpch.2010.6143, 2010.

Shiraiwa, M., Ammann, M., Koop, T., and Pöschl, U.: Gas uptake and chemical aging of semisolid organic aerosol particles, P. Natl. Acad. Sci. USA, 108, 11003-11008, doi:10.1073/pnas.1103045108, 2011.

Swietlicki, E., Hansson, H. C., Hameri, K., Svenningsson, B., Massling, A., McFiggans, G., McMurry, P. H., Petaja, T., Tunved, P., Gysel, M., Topping, D., Weingartner, E., Baltensperger, U., Rissler, J., Wiedensohler, A., and Kulmala, M.: Hygroscopic properties of submicrometer atmospheric aerosol particles measured with H-TDMA instruments in various environments - a review, Tellus B, 60, 432-469, doi:10.1111/j.16000889.2008.00350.x, 2008.

Tang, I. N., Tridico, A. C., and Fung, K. H.: Thermodynamic and optical properties of sea salt aerosols, J. Geophys. Res., 102, 23269-22327, 1997.

Tong, H.-J., Reid, J. P., Bones, D. L., Luo, B. P., and Krieger, U. K.: Measurements of the timescales for the mass transfer of water in glassy aerosol at low relative humidity and ambient temperature, Atmos. Chem. Phys., 11, 4739-4754, doi:10.5194/acp-11-47392011, 2011.

Vaattovaara, P., Huttunen, P. E., Yoon, Y. J., Joutsensaari, J., Lehtinen, K. E. J., O'Dowd, C. D., and Laaksonen, A.: The composition of nucleation and Aitken modes particles during coastal nucleation events: evidence for marine secondary organic contribution, Atmos. Chem. Phys., 6, 4601-4616, doi:10.5194/acp-64601-2006, 2006.

Väkevä, M., Hämeri, K., and Aalto, P. P.: Hygroscopic properties of nucleation mode and aitken mode particles during nucleation bursts and in background air on the west coast of ireland, J. Geophys. Res.-Atmos., 107, 8104, doi:10.1029/2000jd000176, 2002.

Virtanen, A., Joutsensaari, J., Koop, T., Kannosto, J., Yli-Pirila, P., Leskinen, J., Makela, J. M., Holopainen, J. K., Pöschl, U., Kulmala, M., Worsnop, D. R., and Laaksonen, A.: An amorphous solid state of biogenic secondary organic aerosol particles, Nature, 467, 824-827, 2010.

Wagner, R., Möhler, O., Saathoff, H., Schnaiter, M., Skrotzki, J., Leisner, T., Wilson, T. W., Malkin, T. L., and Murray, B. J.: Ice cloud processing of ultra-viscous/glassy aerosol particles leads to enhanced ice nucleation ability, Atmos. Chem. Phys., 12, 85898610, doi:10.5194/acp-12-8589-2012, 2012.

Wang, B., Lambe, A. T., Massoli, P., Onasch, T. B., Davidovits, P., Worsnop, D. R., and Knopf, D. A.: The deposition ice nucleation and immersion freezing potential of 
amorphous secondary organic aerosol: Pathways for ice and mixed phase cloud formation, J. Geophys. Res., 117, D16209, doi:10.1029/2012JD018063, 2012.

Wilson, T. W., Murray, B. J., Wagner, R., Möhler, O., Saathoff, H., Schnaiter, M., Skrotzki, J., Price, H. C., Malkin, T. L., Dobbie, S., and Al-Jumur, S. M. R. K.: Glassy aerosols with a range of compositions nucleate ice heterogeneously at cirrus temperatures, Atmos. Chem. Phys., 12, 8611-8632, doi:10.5194/acp-128611-2012, 2012.

Zhang, Y. H. and Chan, C. K.: Study of contact ion pairs of supersaturated magnesium sulfate solutions using raman scattering of levitated single droplets, J. Phys. Chem. A, 104, 9191-9196, doi:10.1021/jp0013659, 2000.
Zobrist, B., Marcolli, C., Pedernera, D. A., and Koop, T.: Do atmospheric aerosols form glasses?, Atmos. Chem. Phys., 8, 52215244, doi:10.5194/acp-8-5221-2008, 2008.

Zobrist, B., Soonsin, V., Luo, B. P., Krieger, U. K., Marcolli, C., Peter, T., and Koop, T.: Ultra-slow water diffusion in aqueous sucrose glasses, Phys. Chem. Chem. Phys., 13, 3514-3526, doi:10.1039/c0cp01273d, 2011. 